\title{
The potential of PET/MR for brain imaging
}

\author{
Wolf-Dieter Heiss
}

Published online: 23 December 2008

(C) The Author(s) 2008. This article is published with open access at Springerlink.com

\begin{abstract}
Introduction The completion of an integrated PET/MR prototype system for brain imaging is the latest step in the evolution of positron emission tomography. Early images with this new imaging system demonstrate that highresolution multiparametric studies can be combined without significant loss of performance of either imaging modality. Objective This new technology will make fusion of morphological and biological information much easier, yield real-time assessment of complementary variables and will provide dynamic information for kinetic modelling. Simultaneous acquisition of various metabolic and functional parameters may open new insights into the organization of the brain and its changes in disease.

Discussion A new field may open up for molecular and cellular imaging, where new targets - e.g. angiogenesis, gene transfer, function and migration of transplanted cells can be imaged in the morphological context and within a functional environment. This application might have a special impact on the translation of treatment concepts from experimental models into clinical application. If the added value of the hybrid system for diagnosis and treatment monitoring is established, a cost-effective PET/ MR combination might attain wider clinical application.
\end{abstract}

Keywords PET/MR · BrainPET - Image fusion ·

High-resolution biological imaging .

Multi-parametric imaging - Gene transfer and expression .

Cell function and migration

W.-D. Heiss $(\bowtie)$

Max Planck Institute for Neurological Research,

Gleueler Str. 50,

50931 Cologne, Germany

e-mail: wdh@nf.mpg.de

\section{Introduction}

Since the first prototypes $[1,2]$ and the first commercial system [3], positron emission tomography (PET) has developed to multiring systems permitting high resolution and three-dimensional imaging of various physiological, functional and molecular targets. The first applications of PET were in brain research, and despite the many other diagnostic indications, particularly in oncology and cardiology, brain imaging remains a stronghold of PET.

Therefore, this discussion of perspectives of an integrated PET/MR system is focused on research applications in neuroscience to which the combination of PET and MRI may add further impetus. This perspective is in parts speculative and it does not include a discussion of the technical or methodological challenges of combined PET/ MR imaging. These aspects are reviewed elsewhere in the articles of this supplement to EJNMMI.

\section{Development of PET for brain imaging}

The progress in image quality may be followed by metabolic images of glucose consumption in one volunteer acquired on several generation PET systems over the years. The first transaxial image (Fig. 1a) was acquired on a single hexagonal array, the ECAT PET, which covered only the cortical rim. Early PET images suffered from limited spatial resolution (approximately $15 \mathrm{~mm}$ ), low sensitivity and insufficient attenuation and scatter correction [3, 4]. PET image quality improved with the four-ring PC-384 (Scanditronix) [5], which yielded seven simultaneous, partly overlapping transaxial images and that provided a spatial resolution of $8.4 \mathrm{~mm}$ FWHM across 12-mm slices (Fig. 1b) [6] and limited axial reconstruction (Fig. 2). Further improvements came with the 
Fig. 1 Various PET systems over the years demonstrate improvement in image quality and spatial resolution. a ECAT II, spatial resolution $15 \mathrm{~mm}$. b PC384, FWHM 8.4 mm. c ECAT EXACT, FWHM 6.5-7 mm. d ECAT EXACT HR, FWHM 3.6-4.5 mm. e, f HRRT PET: e prototype; f final version (HRRTFV), FWHM 2.3-3.2 mm. Images of glucose metabolism were acquired for $20 \mathrm{~min}$ of steady-state starting $30 \mathrm{~min}$ after tracer administration
1980 ECAT II

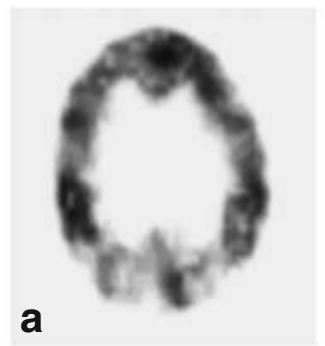

1992 ECAT EXACT HR

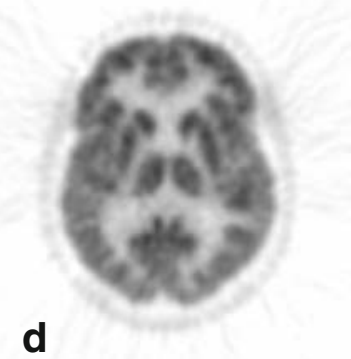

1982 PC-384

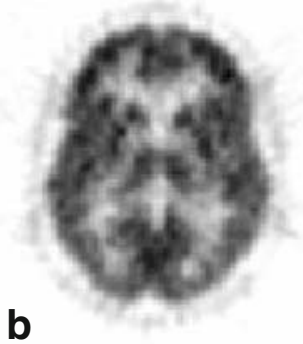

1999 HRRT-PT

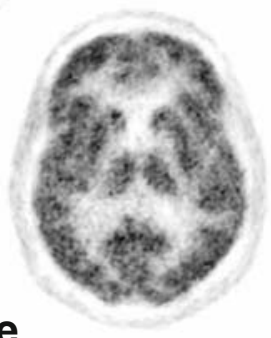

1991 ECAT EXACT

C

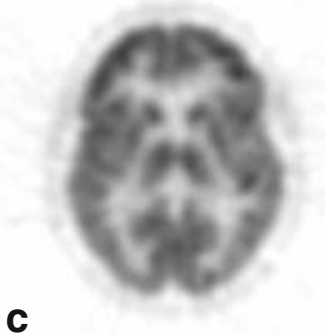

2003 HRRT-FV

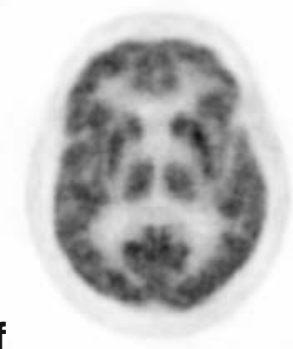

ECAT EXACT PET, which yielded 47 contiguous image planes with a spatial resolution of $6.5-7 \mathrm{~mm}$ and $5-8 \mathrm{~mm}$ in the transverse and axial directions, respectively (Fig. 2) [7]. For the first time the entire brain could be imaged in a single PET examination. The next generation PET system, the ECAT EXACT HR, provided further improvements of the spatial resolution $(3.6 \mathrm{~mm}$ and $4.0 \mathrm{~mm}$ in the transverse and axial direction, respectively), sensitivity and image quality [8] (Figs. 1 and 2). With the dedicated high-resolution research tomograph (HRRT) PET image resolution improved to $2.3 \mathrm{~mm}$ and $2.5 \mathrm{~mm}$ in the transaxial and axial directions, respectively, while sensitivity has increased to $4.3 \%[9,10]$ (Figs. 1 and 2).

The most attractive feature of PET is the high sensitivity and specificity in detecting biochemical and molecular tracers, but it suffers from limited spatial resolution. Therefore, coregistration of PET images with morphological imaging modalities such as CT and MRI has been studied [11, 12], but is not yet in routine clinical use. Research applications of image fusion software have also been challenged by, for example, mapping of molecular and genetic activities to certain cortical areas.

Fig. 2 Coronal views of glucose consumption of

1982 PC-384

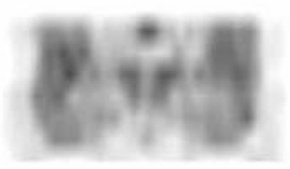

a

1992 ECAT EXACT HR struction was therefore not feasible. b PC-384, slice thickness $12 \mathrm{~mm}$. c ECAT EXACT, axial FWHM 5-8 mm. d ECAT EXACT HR, axial FWHM 4.0-6.7 mm. e, f HRRT PET: e prototype; f final version (HRRT-FV), axial FWHM $2.5-3.4 \mathrm{~mm}$ b

1999 HRRT-PT

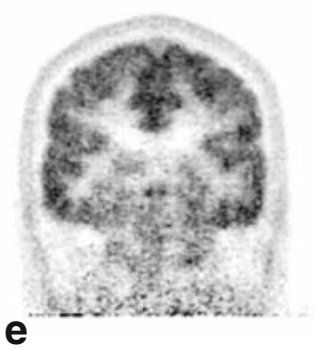

1991 ECAT EXACT

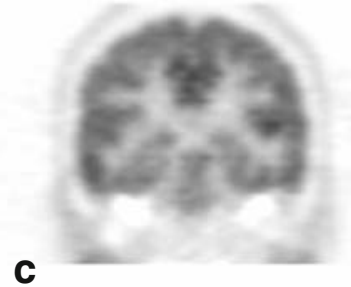

2003 HRRT-FV

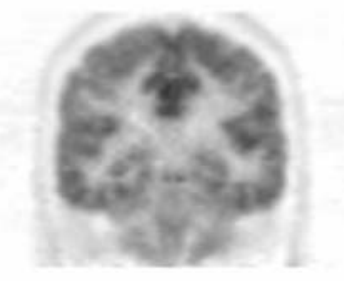

d e

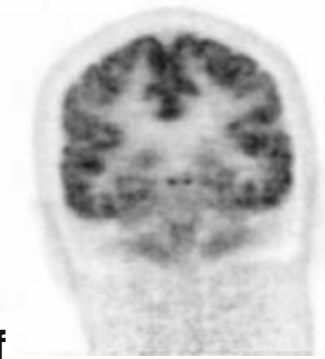


The integration of PET and CT into one imaging system permitting a simple overlay of sequentially acquired images has been a great success in clinical diagnosis [13]. However, because of the limited soft-tissue specificity of CT, this integrated system is not of great value for brain imaging. The installation of a HRRT PET system adjacent to a high-field 7T MRI system allows the utilization of high sensitivity molecular/biochemical and high-resolution anatomical imaging for brain research [14]. However, this system is not integrated and therefore does not permit simultaneous PET and MR data acquisition. For that purpose an integrated PET/MR system is required, which would permit the simultaneous coregistration of various MR and PET procedures. Schmand et al. demonstrated for the first time that simultaneous PET and MR data acquisition is feasible with an integrated PET/MR tomograph [15]. Figure 3 shows the first simultaneously acquired MR and PET images [16] in a volunteer and demonstrates the feasibility of combined MR and PET data acquisition without significant interference between the two modalities. Conventional MR imaging on a 3-T MR tomograph was performed using a T2-weighted turbo-spin echo sequence, a fluid attenuated inversion recovery sequence and a 3-D T1-weighted fast low-angle shot sequence. Additionally, diffusion-weighted imaging, timeof-flight MR angiography (MRA) and proton MR spectroscopy were performed during the acquisition of the PET data. For PET imaging $370 \mathrm{MBq}$ of ${ }^{18} \mathrm{~F}$-fluorodeoxy-Dglucose was intravenously injected and the activity in the head was accumulated over $40 \mathrm{~min}$, starting $20 \mathrm{~min}$ after tracer injection. PET images were reconstructed using a 3DOSEM algorithm following scatter, randoms and attenuation correction. The resolution of the reconstructed images was $2.5 \mathrm{~mm}$ FWHM at the centre and $4.5 \mathrm{~mm}$ at $10 \mathrm{~cm}$ offaxis with a sensitivity of $5.6 \%$. Overall, the quality of the images was comparable to that of the corresponding standalone PET and MRI systems [16].

\section{Advantages of an integrated PET/MR system for image fusion}

With the installation of PET/MR systems in a clinical environment, this integrated imaging modality, which is
Fig. $3 \mathrm{PET} / \mathrm{MR}$ imaging with BrainPET system in a volunteer. Three representative orthogonal slices demonstrate the alignment of anatomic (3-D T1weighted MRI) and metabolic images (FDG-PET). Asymmetries in the frontotemporal cortex are related to small white matter hyperintensities

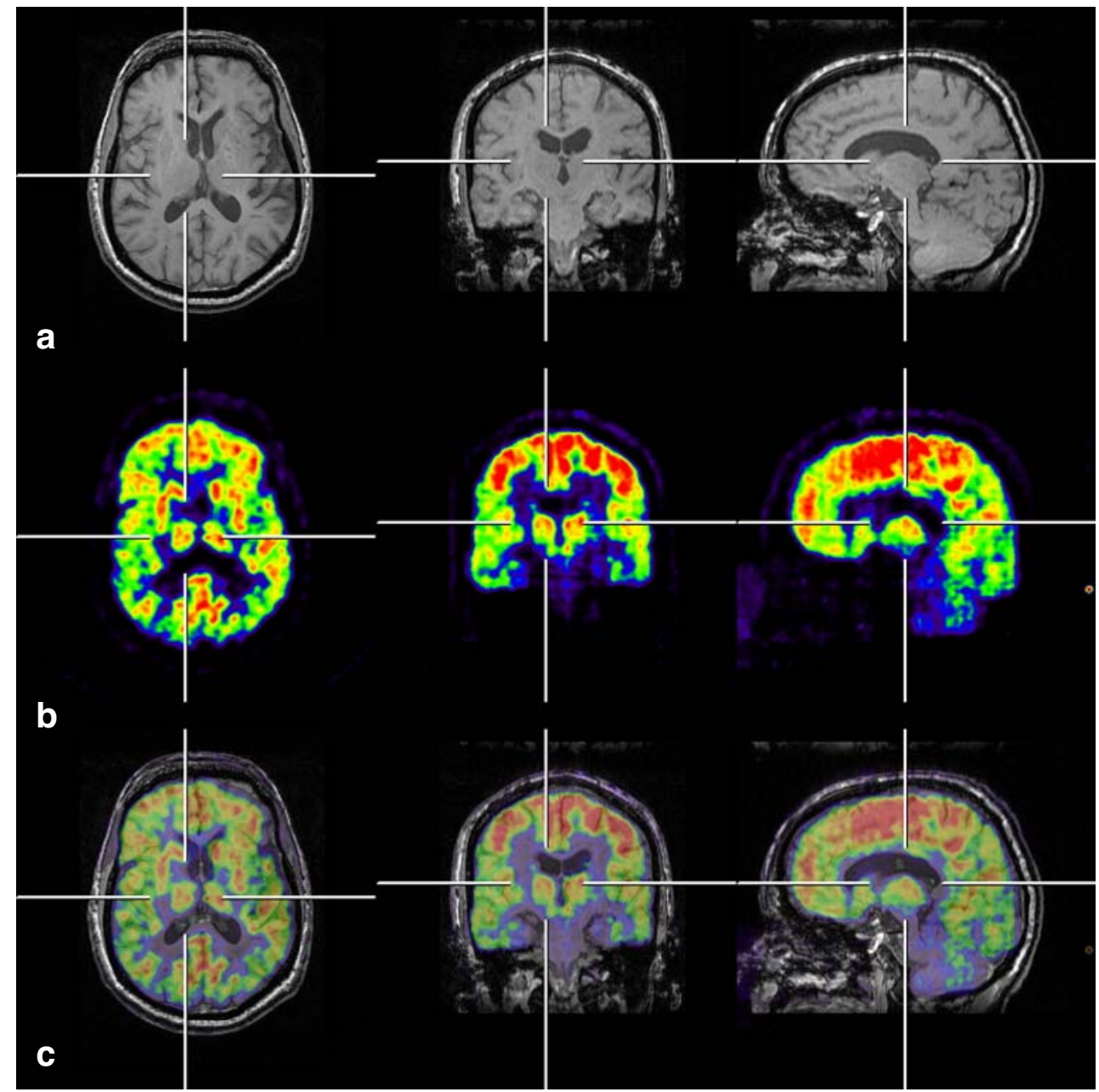


already utilized in preclinical research already is on the verge of being applied to the clinical neurosciences [17, 18]. An integrated PET/MRI system will permit the simultaneous acquisition of several parameters (Table 1). Quantitative values from PET (some in the picomolar range) of a large number of biological parameters are complemented by the high-resolution information provided by MRI (in the micromolar range) to yield complementary information of previously unexpected variability.

The combination of imaging modalities for high sensitivity and high resolution with the additional advantage of utilizing dynamic acquisition procedures appears very appealing for a variety of clinical and research applications. Recently, PET data and MRI data have been retrospectively combined for detection and staging of gliomas $[19,20]$ as well as for identification of areas with critical neurofunction in the vicinity of tumours, which is important for planning surgery [21]. Image fusion has gained a place in the early diagnosis of dementia and mild cognitive impairment [22] and degenerative disorders, e.g. cerebral atrophy and Huntington chorea. Image fusion is of clinical value in the detection of epileptic foci accessible for surgery [23] and for the identification of metabolic activity, transmitter concentration and enzyme expression in small brain structures [24]. In experimental focal brain ischaemia and ischaemic stroke, coregistration of regional values for cerebral blood flow, oxygen utilization and glucose metabolism on early and late MRI has permitted the differentiation of irreversibly damaged areas and functionally impaired but morphologically preserved areas, thus affecting treatment strategies [25].

Table 1 Assessment of biological properties by MRI and PET

\begin{tabular}{ll}
\hline MRI & PET \\
\hline Morphology & Flow $\left(\mathrm{H}_{2}{ }^{15} \mathrm{O}\right)$ \\
Water motion in tissue (DWI) & Metabolism (FDG) \\
Vascular anatomy (MRA) & Blood volume $\left(\mathrm{C}^{15} \mathrm{O}\right)$ \\
Perfusion (PWI, DCE-MRI) & Oxygen consumption $\left({ }^{15} \mathrm{O}\right)$ \\
Tissue metabolites & Vascular permeability \\
(MRS for $\left.{ }^{1} \mathrm{H},{ }^{13} \mathrm{C},{ }^{23} \mathrm{Na},{ }^{31} \mathrm{P}\right)$ & (labelled AA) \\
Functional activation $(\mathrm{fMRI})$ & Nucleic acid synthesis (FLT) \\
Cerebral fibre tracts $(\mathrm{DTI})$ & Transmitters (e.g. DOPA) \\
Oxygen consumption $\left({ }^{17} \mathrm{O}\right)$ & Receptors (e.g. raclopride) \\
Migration of cells (Fe labelling) & Enzymatic activity (e.g. MP4A) \\
& Angiogenesis (e.g. $\left.{ }^{18} \mathrm{~F}-\mathrm{RGB}\right)$ \\
& Distribution and kinetics of \\
tracers and drugs (labelled
\end{tabular}

\section{Real-time imaging of complementary information}

The established applications of coregistered MRI and PET will gain new dimensions with the simultaneous procedures made possible by integrated PET/MR. Simultaneous data acquisition will allow the addition of kinetic, functional and metabolic information for real-time multiparametric imaging. The vascular origin of changes in cerebral blood flow, oxygen consumption and metabolism causing stroke and intracerebral and subarachnoid haemorrhages can be detected by MRA. Perfusion changes can be related directly to the extent of hypoxia $\left({ }^{18} \mathrm{~F}-\mathrm{MISO}-\mathrm{PET}\right)$ and changes in metabolic markers (e.g. lactate, choline and $N$-acetylaspartate) can be assessed through simultaneous PW-MRI, MRS and ${ }^{18} \mathrm{~F}$-MISO-PET. Diffusion- and perfusion-weighted (DW-PW) MRI can be performed during PET measurements of ${ }^{15} \mathrm{O}$ and $\mathrm{H}_{2}{ }^{15} \mathrm{O}$ for differentiation of intervascular perfusion, tissue blood flow, penumbra and irreversible tissue damage in ischaemic stroke [26]. This differentiation is important for therapeutic decision. For that purpose the validation of MR surrogate measures (mismatch between PW- and DW-MRI) is needed. The combination of various MRS procedures with PET will broaden the insight into the complex metabolic changes caused by brain diseases.

Coregistration of image data from the different modalities has indicated the value of such comparative studies in stroke [27], gliomas [28], and degenerative [29] and congenital or hereditary disorders [30]. However, coregistration was limited since it required multiple investigations in different laboratories. Real-time simultaneous studies will be of particular interest for the interpretation of activation patterns (intravascular versus tissue signals) obtained with fMRI and $\mathrm{H}_{2}{ }^{15} \mathrm{O}$ (or FDG) PET [31, 32] and will be useful for the analysis of the effect of specific tasks on transmitter release and receptor binding, such as the determination of DOPA, raclopride and 5-hydroxytryptamine transporter by combining fMRI with PET [3335]. A similar approach (fMRI and PET of receptor ligands) might be useful to elucidate the effects of drugs and their withdrawal (e.g. nicotine) on task performance. However, in these combined applications of fMRI and PET the differences in temporal resolution and sampling must be considered: separated short time frame MRI ( seconds) versus PET acquisitions of several minutes.

\section{Dynamic data for modelling}

The high temporal resolution of MRI can be utilized for the acquisition of dynamic data can be utilized for the quantification of metabolic values by PET. For example, flowdependent kinetic constants can be determined by PWI and used for compartmental analysis of PET data (e.g. FDG, FLT) 


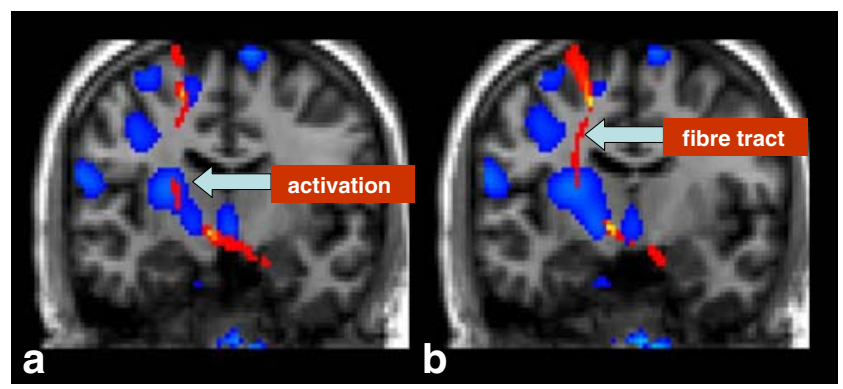

Fig. 4 Coregistration of MRI with diffusion tensor tracking and PET ${ }^{15} \mathrm{O}$ water activation studies demonstrates the effect of stimulation of the nucleus accumbens by flow increase in the striatum and various cortical regions. Diffusion tractography depicts the anatomical pathways between the stimulated region and the activated subcortical and cortical areas
[36] or for the assessment of the kinetics of the distribution of tracers or labelled drugs in various brain structures [37].

Simultaneous data acquisition by MRI and PET could also be used to develop new methods, e.g. values of cerebral blood flow obtained by arterial spin labelling MRI can be validated by $\mathrm{H}_{2}{ }^{15} \mathrm{O}$-PET [38], and ${ }^{17} \mathrm{O}$ as a new MRI tracer for oxygen utilization [39] can be compared to cerebral metabolic rate of $\mathrm{O}_{2}$ as determined by PET. This promising new MRI method uses inhalation of air enriched with ${ }^{17} \mathrm{O}_{2}$ whereby the inhaled ${ }^{17} \mathrm{O}$ is converted into $\mathrm{H}_{2}{ }^{17} \mathrm{O}$ in proportion to the oxygen consumption. The metabolite $\mathrm{H}_{2}{ }^{17} \mathrm{O}$ perturbs the proton signal resulting in negative contrast on T2-weighted MRI. Thus, the signal intensity is proportional to oxygen consumption.
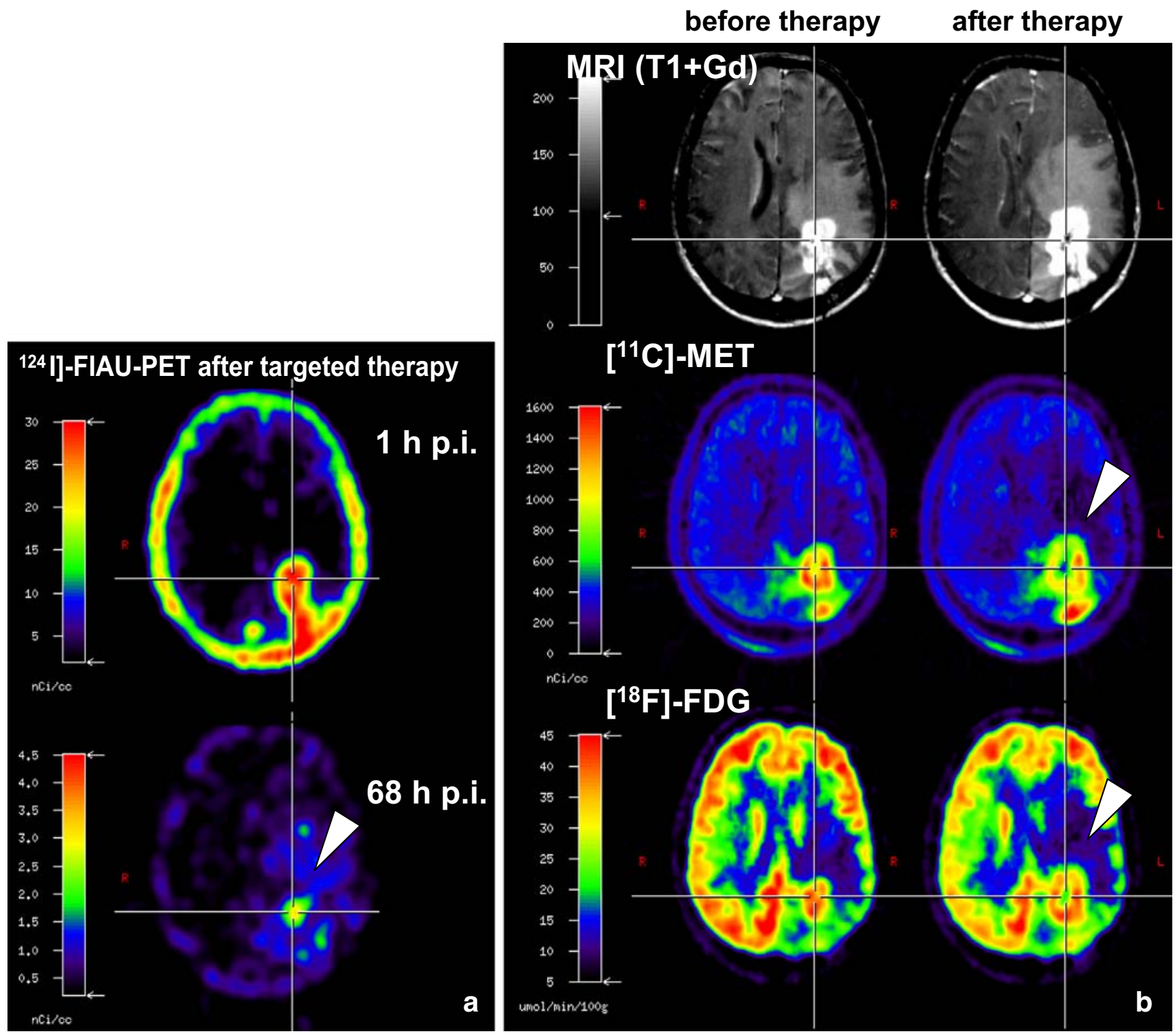

Fig. 5 Coregistration of FIAU-PET, MET-PET, FDG-PET and MRI for evaluation after targeted therapy in the active tumour centres, the effect of ganciclovir treatment is represented by the necrosis developing in the region of fialuridine accumulation. From Jacobs et al. [44] 
Fig. 6 Images of stem cell migration toward the stroke territory by 3 -D T2*-weighted MRI $(\mathbf{a}, \mathbf{b})$ and assessment of functional activity of implanted cells after migration to the stroke border zone $(\mathbf{c}, \mathbf{d})$. Yellow arrows indicate the implantation site (a), red arrows indicate migrating stem cells $(\mathbf{a}, \mathbf{b})$ Immunohistochemistry indicates differentiation of stem cells (green fluorescent protein) into neurons (neuronal specific nuclear protein) (c) and glial cells (glial fibrillary acidic protein) (d). From Hoehn et al. [47]
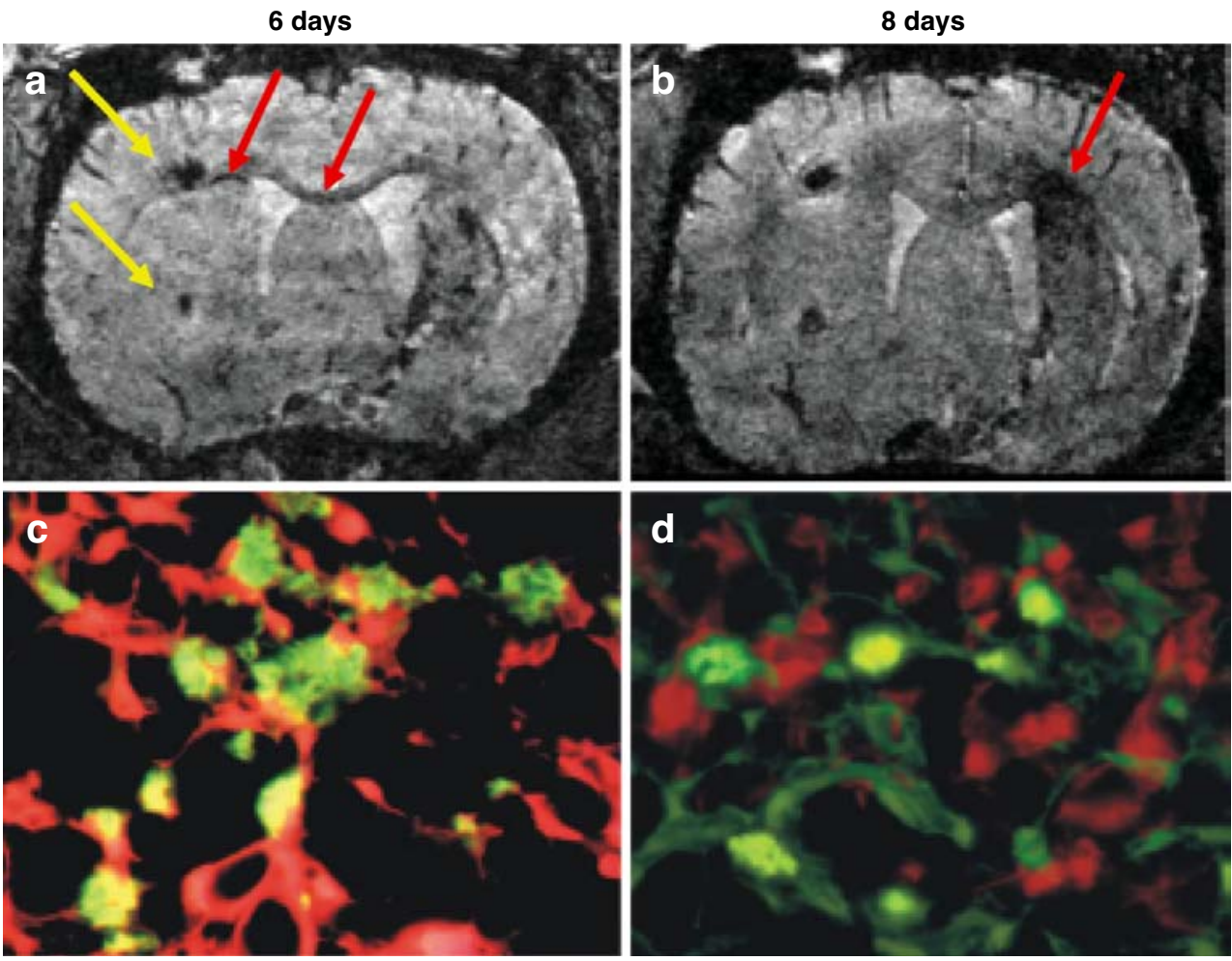

$\mathrm{GFP}^{+} / \mathrm{NeuN}^{+}$

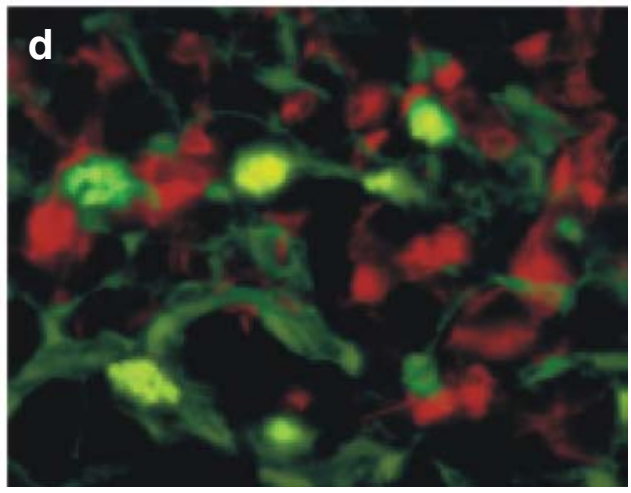

GFP $^{+} /$GFAP $^{+}$

\section{Multiparametric functional imaging}

For complex studies of brain function special combinations of modalities or additional investigative procedures may open new insights into the organization of the brain and diseasesrelated changes of brain function. For these studies diffusion tensor tracking will add new dimensions, since it could be performed in close temporal relation to activation studies mapping the effects on transmitter release and receptor occupancy as well as on metabolism in connected areas of functional networks [40]. With this approach the effect of deep brain stimulation, which is a means to ameliorate neurological symptoms and to improve abnormal behaviour [41] could be demonstrated. The effect of such an invasive manipulation on metabolism in defined regions together with the connecting fibre tracts is shown in Fig. 4. It may also be possible to analyse the effect of repetitive transcranial magnetic stimulation (rTMS), which can be used to activate or inhibit selected areas of the cortex, on regional metabolism, and on the involvement of transmitter/receptor systems and the connecting network [42].

\section{Perspectives for molecular and cellular imaging}

Fusion of PET and MR images has been used in several attempts to identify molecular events induced by local pathogenetic factors, by the transfer of genetic material or implantation of (stem) cells. While the above studies were performed using separate imaging modalities, it is possible that these concepts could be transferred more easily to routine applications in humans through an integrated PET/ MR tomograph, by which various functional and morphological aspects can be observed simultaneously. In several of these applications the identification of small regions or cell clusters by MRI might be essential for the analysis of biochemical processes by PET. Therefore, these examples may create new combined applications of MR and PET.

Angiogenesis is a fundamental process in various physiological and pathological processes. Visualization, quantification and monitoring of angiogenesis is of interest in various fields, including oncology and cardiology. Molecules regulating angiogenesis include growth factor receptors and integrins. Cyclic RGD peptides bind to integrin $\alpha_{v} \beta_{3}$, and ${ }^{18} \mathrm{~F}$-galacto-RGD has been tested in humans with high uptake in highly vascularized tumours. Alternatively, labelled ligands have been used to study the vascular endothelial growth factor receptor. When combined with dynamic, contrast-enhanced MR, yielding vascular and extravascular volumes, vascular permeability and perfusion angiogenesis PET markers may permit the follow-up of angiogenetic and antiangiogenetic treatment [43].

Targeted gene transfer by various vectors can be used to express foreign enzymes in cells. This strategy can be 
applied to make malignant cells susceptible to specific drugs, which are toxic only to those cells expressing the enzymes. In an experimental glioma model the efficacy of this treatment strategy with transfer of the herpes virus thymidine kinase gene and application of ganciclovir has been demonstrated and preliminary clinical tests have shown some efficacy of this treatment [44]. The effect of this therapy can be followed by multitracer PET and verified on MRI (Fig. 5).

Implantation of embryonic stem cells into the striatum lesioned by injection of 6-OHDA in rats leads to proliferation and differentiation of dopaminergic cells. This was demonstrated by coregistering MRI and PET of the specific dopamine transporter ligands ${ }^{11} \mathrm{C}$-CFT $\left[{ }^{11} \mathrm{C}-2 \beta\right.$-carbomethoxy-3 $\beta$-(4-fluorophenyl) tropane] where CFT binding was restored in the region of $\mathrm{TH}$-immunoreactive neurons documented post mortem. The restored functional activity of these implanted cells was demonstrated by the response to amphetamine, which caused an increase in $\mathrm{rCBV}$ due to dopamine release [45]. Simultaneous PET/MR can be used to show the viability and differentiation of transplanted cells and their effect on neuronal networks [46]

Cell replacement approaches are an innovative strategy for treatment of various neurological disorders. For the development of these approaches in animal models it is essential to monitor the location and to follow the migration of grafted stem or progenitor cells. Various strategies have been proposed for labelling these cells with ultrasmall superparamagnetic iron oxide particles and micron-sized iron oxide particles [47]. In focal experimental ischaemia labelled stem cells migrated over 3 weeks from the contralateral implantation site along the corpus callosum to the ventricular walls and massively populated the border zone of the damaged brain tissue on the lesioned hemisphere (Fig. 6). A combination of MRI for tracking cells and of PET for proving their biological activity could demonstrate the viability of the cells as well as their integration into functional networks [48]. Monitoring cell viability and migration by MRI combined with indicators of function from PET might also become a qualifying step in strategies relying on transplantation of fetal grafts, e.g. in Parkinson disease.

\section{Conclusion}

Integrated PET/MR holds great potential for brain research, especially for multiparametric analysis of complex function in neuronal networks, for the imaging of complex molecular processes of gene transfer and cell transplantation and for the translation of new treatment strategies from preclinical research into clinical application. If the superiority of integrated PET/MR in diagnostic accuracy and treatment monitoring can be proven and if the integration of the two modalities is cost effective it may also become an instrument for routine clinical use.

Conflicts of interest Wolf-Dieter Heiss is a consultant for Siemens Molecular Imaging, Knoxville, TN.

Open Access This article is distributed under the terms of the Creative Commons Attribution Noncommercial License which permits any noncommercial use, distribution, and reproduction in any medium, provided the original author(s) and source are credited.

\section{References}

1. Ter-Pogossian MM, Phelps ME, Hoffman EJ, Mullani NA. A positron emission transaxial tomograph for nuclear imaging (PETT). Radiology 1975;114:89-98.

2. Cho ZH, Chan JK, Eriksson L. Circular ring transverse axial positron camera for 3-dimensional reconstruction of radionuclides distribution. IEEE Trans Nucl Sci 1976;23:613-22.

3. Phelps ME, Hoffman EJ, Huang SC, Kuhl DE. ECAT: a new computerized tomographic imaging system for positron-emitting radiopharmaceuticals. J Nucl Med 1978;19:635-47.

4. Heiss WD, Vyska K, Kloster G, Traupe H, Freundlieb C, Hoeck A, et al. Demonstration of decreased functional activity of visual cortex by [11C]methylglucose and positron emission tomography. Neuroradiology 1982;23:45-7.

5. Eriksson L, Bohm C, Kesselberg M, Blomqvist G, Litton J, Widen L, et al. A four ring positron camera system for emission tomography of the brain. IEEE Trans Nucl Sci 1982;29:539-43.

6. Heiss WD, Pawlik G, Herholz K, Wagner R, Göldner H, Wienhard $\mathrm{K}$. Regional kinetic constants and CMR glu in normal human volunteers determined by dynamic positron emission tomography of [18 F]-2-fluoro-2-deoxy-D-glucose. J Cereb Blood Flow Metab 1984;4:212-23.

7. Wienhard K, Eriksson L, Grootoonk S, Casey M, Pietrzyk U, Heiss WD. Performance evaluation of the positron scanner ECAT EXACT. J Comput Assist Tomogr 1992;16:804-13.

8. Wienhard K, Dahlbom M, Eriksson L, Michel C, Bruckbauer T, Pietrzyk U, et al. The ECAT EXACT HR: performance of a new high resolution positron scanner. J Comput Assist Tomogr 1994;18:110-8.

9. Wienhard K, Schmand M, Casey ME, Baker K, Bao J, Eriksson L, et al. The ECAT HRRT: Performance and first clinical application of the new high resolution research tomograph. IEEE Trans Nucl Sci 2002;49:104-10.

10. de Jong HWAM, van Velden FHP, Kloet RW, Buijs FL, Boellaard R, Lammertsma AA. Performance evaluation of the ECAT HRRT: an LSO-LYSO double layer high resolution, high sensitivity scanner. Phys Med Biol 2007;52:1505-26.

11. Pietrzyk U, Herholz K, Schuster A, von Stockhausen HM, Lucht H, Heiss WD. Clinical applications of registration and fusion of multimodality brain images from PET, SPECT, CT, and MRI. Eur J Radiol 1996;21:174-82.

12. Cizek J, Herholz K, Vollmar S, Schrader R, Klein J, Heiss WD. Fast and robust registration of PET and MR images of human brain. Neuroimage 2004;22:434-42.

13. Beyer T, Townsend DW, Brun T, Kinahan PE, Charron M, Roddy R, et al. A combined PET/CT scanner for clinical oncology. J Nucl Med 2000;41:1369-79. 
14. Cho ZH, Son YD, Kim HK, Kim KN, Oh SH, Han JY, et al. A fusion PET-MRI system with a high-resolution research tomograph-PET and ultra-high field 7.0 T-MRI for the moleculargenetic imaging of the brain. Proteomics 2008;8:1302-23.

15. Schmand M, Burbar Z, Corbeil JL, Zhang N, Michael C, Byars L, et al. BrainPET: First human tomograph for simultaneous (functional) PET and MR imaging. J Nucl Med 2007;48(Suppl 2):45P.

16. Schlemmer HP, Pichler BJ, Schmand M, Burbar Z, Michel C, Ladebeck R, et al. Simultaneous MR/PET imaging of the human brain: feasibility study. Radiology 2008;248:1028-35.

17. Judenhofer MS, Wehrl HF, Newport DF, Catana C, Siegel SB, Becker M, et al. Simultaneous PET-MRI: a new approach for functional and morphological imaging. Nat Med 2008;14:459-65.

18. Catana C, Procissi D, Wu Y, Judenhofer MS, Qi J, Pichler BJ, et al. Simultaneous in vivo positron emission tomography and magnetic resonance imaging. Proc Natl Acad Sci USA 2008;105:3705-10.

19. Jacobs AH, Kracht LW, Gossmann A, Ruger MA, Thomas AV, Thiel A, et al. Imaging in neurooncology. NeuroRx. 2005;2:333-47.

20. Chen W. Clinical applications of PET in brain tumors. J Nucl Med 2007;48:1468-81.

21. Thiel A, Habedank B, Herholz K, Kessler J, Winhuisen L, Haupt WF, et al. From the left to the right: how the brain compensates progressive loss of language function. Brain Lang 2006;98:57-65.

22. Herholz K. PET studies in dementia. Ann Nucl Med 2003;17:79-89.

23. Koepp MJ, Woermann FG. Imaging structure and function in refractory focal epilepsy. Lancet Neurol 2005;4:42-53.

24. Eggers C, Szelies B, Bauer B, Wienhard K, Schroder H, Herholz K, et al. Imaging of acetylcholine esterase activity in brainstem nuclei involved in regulation of sleep and wakefulness. Eur J Neurol 2007;14:690-3.

25. Heiss WD. Ischemic penumbra: evidence from functional imaging in man. J Cereb Blood Flow Metab 2000;20:1276-93.

26. Heiss WD, Sobesky J, Hesselmann V. Identifying thresholds for penumbra and irreversible tissue damage. Stroke 2004;5:2671-4.

27. Lanfermann H, Kugel H, Heindel W, Herholz K, Heiss WD, Lackner K. Metabolic changes in acute and subacute cerebral infarctions: findings at proton MR spectroscopic imaging. Radiology 1995;196:203-10.

28. Herholz K, Heindel W, Luyten PR, denHollander JA, Pietrzyk U, Voges $\mathrm{J}$, et al. In vivo imaging of glucose consumption and lactate concentration in human gliomas. Ann Neurol 1992;31:319-27.

29. Mielke R, Schopphoff HH, Kugel H, Pietrzyk U, Heindel W, Kessler J, et al. Relation between 1H MR spectroscopic imaging and regional cerebral glucose metabolism in Alzheimer's disease. Int J Neurosci 2001;107:233-45.

30. Duncan DB, Herholz K, Kugel H, Roth B, Ruitenbeek W, Heindel W, et al. Positron emission tomography and magnetic resonance spectroscopy of cerebral glycolysis in children with congenital lactic acidosis. Ann Neurol 1995;37:351-8.

31. Buxton RB, Uludag K, Dubowitz DJ, Liu TT. Modeling the hemodynamic response to brain activation. Neuroimage 2004;23 (Suppl 1):S220-33.

32. Fox PT, Raichle ME. Focal physiological uncoupling of cerebral blood flow and oxidative metabolism during somatosensory stimulation in human subjects. Proc Natl Acad Sci USA 1986;83:1140-44.

33. Piccini P, Brooks DJ. New developments of brain imaging for Parkinson's disease and related disorders. Mov Disord 2006;21:2035-41.

34. Rhodes RA, Murthy NV, Dresner MA, Selvaraj S, Stavrakakis N, Babar S, et al. Human 5-HT transporter availability predicts amygdala reactivity in vivo. J Neurosci 2007;27:9233-7.

35. Landau SM, Lal R, O’Neil JP, Baker S, Jagust WJ. Striatal dopamine and working memory. Cereb Cortex 2008; [Epub ahead of print]. doi:10.1093/cercor/bhn095.

36. Schmidt KC, Turkheimer FE. Kinetic modeling in positron emission tomography. Q J Nucl Med 2002;46:70-85.

37. Weber WA, Czernin J, Phelps ME, Herschman HR. Technology Insight: novel imaging of molecular targets is an emerging area crucial to the development of targeted drugs. Nat Clin Pract Oncol 2008;5:44-54.

38. Leontiev O, Buxton RB. Reproducibility of BOLD, perfusion, and $\mathrm{CMRO} 2$ measurements with calibrated-BOLD fMRI. Neuroimage 2007:35:175-84.

39. Tailor DR, Baumgardner JE, Regatte RR, Leigh JS, Reddy R. Proton MRI of metabolically produced $\mathrm{H} 217 \mathrm{O}$ using an efficient $17 \mathrm{O} 2$ delivery system. Neuroimage 2004;22:611-8.

40. Song AW, Harshbarger T, Li T, Kim KH, Ugurbil K, Mori S, et al. Functional activation using apparent diffusion coefficient-dependent contrast allows better spatial localization to the neuronal activity: evidence using diffusion tensor imaging and fiber tracking. Neuroimage 2003;20:955-61.

41. Sturm V, Lenartz D, Koulousakis A, Treuer H, Herholz K, Klein JC, et al. The nucleus accumbens: a target for deep brain stimulation in obsessive-compulsive- and anxiety-disorders. J Chem Neuroanat 2003;26:293-299.

42. Thiel A, Schumacher B, Wienhard K, Gairing S, Kracht LW, Wagner R, et al. Direct demonstration of transcallosal disinhibition in language networks. J Cereb Blood Flow Metab 2006;26:1122-7.

43. Hsu AR, Chen $X$. Advances in anatomic, functional, and molecular imaging of angiogenesis. J Nucl Med 2008;49:511-4.

44. Jacobs A, Voges J, Reszka R, Lercher M, Gossmann A, Kracht L, et al. Positron-emission tomography of vector-mediated gene expression in gene therapy for gliomas. Lancet 2001;358:727-9.

45. Bjorklund LM, Sanchez-Pernaute R, Chung S, Andersson T, Chen IY, McNaught KS, et al. Embryonic stem cells develop into functional dopaminergic neurons after transplantation in a Parkinson rat model. Proc Natl Acad Sci USA 2002;99: 2344-9.

46. Piccini P, Pavese N, Hagell P, Reimer J, Bjorklund A, Oertel $\mathrm{WH}$, et al. Factors affecting the clinical outcome after neural transplantation in Parkinson's disease. Brain 2005;128:297786.

47. Hoehn M, Himmelreich U, Kruttwig K, Wiedermann D. Molecular and cellular MR imaging: potentials and challenges for neurological applications. J Magn Reson Imaging 2008;27:941-54.

48. Bliss T, Guzman R, Daadi M, Steinberg GK. Cell transplantation therapy for stroke. Stroke 2007;38:817-26. 